\title{
LIBERTAD, DEBER DE JUSTICIA E IDENTIFICACIÓN DEL DERECHO *
}

\author{
Mariano C. Melero de la Torre
}

UNED

RESUMEN. Este trabajo toma como punto de partida un argumento típico de la filosofía política moderna - las normas jurídicas de un Estado razonablemente justo son moralmente obligatorias porque cumplen un papel indispensable en la realización de la libertad de sus ciudadanos-. Frente a su lectura más ortodoxa, basada en la idea del "gobierno por consentimiento", el autor desarrolla el «modelo del deber natural», que afirma una relación objetiva entre el Estado de Derecho y la libertad individual, y donde la base común de la obligación política es el principio de la integridad de la justicia. Dicho modelo se corresponde, a su vez, con una concepción interpretativa del Derecho cuya principal tesis contradice al positivismo jurídico en un aspecto esencial: la identificación de las normas jurídicas depende, en parte, de la justificación moral de su fuerza obligatoria.

Palabras clave: libertad, obligación política, positivismo jurídico, identificación de las normas.

ABSTRACT. This paper takes as its point of departure a typical argument of modern political philosophy - legal norms of a reasonably just state are morally obligatory because they play an indispensable role in the realization of its citizens' freedom. In contrast with the most orthodox version of this argument, based on the idea of «government by consent», the author develops the «model of natural duty", that presupposes an objective relationship between the rule of law and individual liberty, and where the common basis of political obligation is the principle of integrity of justice. Furthermore, this model corresponds with an interpretative conception of law whose principal thesis refutes legal positivism in an essential aspect: the identification of legal norms does not only depend upon social conventions, but also on the moral justification of their normative force. norms.

Keywords: freedom, political obligation, legal positivism, the identification of legal

\footnotetext{
* Fecha de recepción: 28 de febrero de 2008. Fecha de aceptación: 26 de marzo de 2008.
} 


\section{LA OBLIGACIÓN POLÍTICA COMO PROBLEMA}

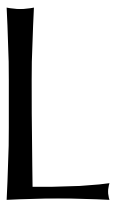

a posible justificación de una obligación moral general de obediencia al Derecho, si bien es una cuestión que corresponde dilucidar a la filosofía moral y política, incide decisivamente en la teoría general del Derecho, y más concretamente, en el problema de la identificación y existencia del fenómeno jurídico. Ésta es, al menos, la tesis principal de este trabajo. Plantearé la primera cuestión en el ámbito de la historia de la filosofía política, con el propósito de esbozar un modelo de justificación de la obligación política, para luego entrar a discutir el segundo problema dentro de la filosofía jurídica contemporánea.

En términos generales, las teorías que afirman la existencia de una obligación de este tipo pueden dividirse en dos grandes grupos, según cuál sea la condición que emplean para su justificación. En el primer grupo estarían aquellas teorías que exigen la adquisición voluntaria por parte de los ciudadanos — ya sea mediante la aceptación de los principios que rigen el sistema jurídico, ya sea mediante la obtención de los beneficios procedentes de ese sistema- Las teorías del segundo grupo, en cambio, serían las que postulan un deber moral de obediencia al Derecho de un Estado razonablemente justo, con independencia de la voluntad de los ciudadanos. A este segundo grupo lo denominaré «el modelo del deber natural de justicia» ${ }^{1}$.

El presente trabajo pretende bosquejar un argumento en pro de la obligación política dentro del marco teórico de dicho modelo. Para ser más precisos, la concepción que aquí se defiende afirma la existencia de un deber «natural» — cuyo origen no reside en nada que podamos hacer o decir- de obedecer las instituciones políticas de un Estado de Derecho, entendiendo por tales instituciones la realización jurídica de los principios de justicia de una democracia liberal. Con esta tesis pretendo dar réplica al escepticismo que, sobre este tema, ha llegado a convertirse en un lugar común tanto en la esfera de la filosofía política como en la de la filosofía del Derecho ${ }^{2}$. A mi modo de ver, esta actitud escéptica es la consecuencia de asumir la aceptación voluntaria como la única condición posible de la obligación política; el propósito último de este trabajo es precisamente rebatir dicho presupuesto.

Pero antes de empezar a desarrollar el argumento, permítaseme añadir algo más sobre la noción misma de «obligación política». En primer lugar, un breve comentario sobre su definición. Afirmar la existencia de una obligación moral general de obedecer el Derecho significa defender que todos los ciudadanos de una comunidad política tienen, bajo ciertas condiciones, la obligación de obedecer todas y cada una de las directivas jurídicas de su sistema legal precisamente porque forman parte de dicho sistema ${ }^{3}$.

${ }^{1}$ En el texto se usarán indistintamente los términos «deber»y «obligación». A pesar de los intentos por marcar una diferenciación teórica entre ambos, no existe un consenso generalizado al respecto, por lo que he preferido partir de su equiparación. Para una descripción general de la polémica sobre esta distinción, $c f r$. N. M. ${ }^{a}$ MarTíneZ YÁÑEZ, 2000, La obediencia al Derecho en la España democrática, Madrid: Dykinson.

2 Cfr. M. B. E. Smith, 1973, «Is There a Prima Facie Obligation to Obey the Law?», Yale Law Journal, 82; J. Simmons, 1979, Moral Principles and Political Obligations, Princeton University Press; L. GreEn, 1988, The Authority of the State, Oxford: Clarendon Press; J. Raz, 1994, Ethics in the Public Domain, Oxford: Clarendon Press.

Aquí sigo la práctica habitual de considerar las directivas como el caso modélico de los contenidos del Derecho. Evidentemente, el sistema jurídico modifica nuestra situación normativa de formas muy variadas, es- 
Dicho con mayor brevedad, implica aseverar que estamos obligados a obedecer el Derecho por ser Derecho. Lo cual no implica que éste deba ser la única base normativa de las acciones que prescribe. En muchas ocasiones, las normas jurídicas ordenan lo que previamente nos impone la moral, si bien de un modo más concreto y con carácter coactivo. Sin embargo, como ha señalado J. RAZ, un argumento en pro de la obligación política no puede limitarse a mostrar que el Derecho modifica de algún modo nuestras obligaciones morales previas, o que, en general, transforma nuestra situación normativa (mediante la imposición de derechos, permisos, etc.) ${ }^{4}$. Para alcanzar su objetivo, dicho argumento debe mostrar que el Derecho obliga por sí mismo, es decir, en virtud de su mera existencia.

No es suficiente, por tanto, con constatar que tenemos una obligación moral de obedecer las normas jurídicas cuando su contenido coincide con lo que nos dicta nuestra conciencia moral ${ }^{5}$. Es cierto que casi todas las teorías de la obligación política asumen que no hay ningún deber de obediencia cuando la injusticia de las normas jurídicas sobrepasa ciertos límites — razón por la cual se suele decir que la obligación política es únicamente prima facie-. Sin embargo, dado que ningún sistema jurídico es (ni será nunca) perfectamente justo, no tendría mucho sentido afirmar una obligación general de obediencia si no fuéramos capaces de justificar que, en ciertas ocasiones, existe la obligación moral de obedecer normas injustas — es decir, normas que no se ciñen a nuestra particular concepción de la justicia-. Como veremos, el argumento del deber natural de justicia reconoce este punto.

En segundo lugar, resulta evidente, a partir de su definición misma, que se trata de una cuestión que incide decisivamente en el problema de la identificación del Derecho $^{6}$. En definitiva, no es posible establecer la existencia de una obligación general de obediencia al Derecho sin postular una condición moral intrínseca a la realidad jurídica. Lo cual nos conduce a descartar las teorías de la aceptación voluntaria. Al recurrir

tableciendo permisos, títulos, derechos, etc. Por este motivo, algunos autores prefieren hablar de fidelidad, o de responsabilidad, en lugar de obediencia. Para los propósitos de este artículo, sin embargo, no he creído necesario introducir esta complejidad.

${ }^{4}$ The Authority of Law, Oxford: Oxford University Press, 1979, p. 234; Ethics in the Public Domain, op.cit., pp. 343-344.

5 Ésta es, de hecho, la forma en que los iusfilósofos españoles han solido defender la obligación política a partir del planteamiento que realizó F. GONZÁLEZ VICÉN1 1979, sobre la cuestión («mientras no hay un fundamento ético para la obediencia la Derecho, sí hay un fundamento ético absoluto para su desobediencia», «La obediencia al Derecho», Estudios de Filosofía del Derecho, Universidad de la Laguna, p. 388). Es el caso, por ejemplo, de M. ATIENZA, 1983, «La filosofía del Derecho de Felipe González Vicén», en El lenguaje del Derecho. Homenaje a Genaro R. Carrió, Buenos Aires: Abeledo-Perrot; E. DíAz, 1984, De la maldad estatal y la soberanía popular, Madrid: Debate; y E. FERnÁnDEZ, 1987, La obediencia al Derecho, Madrid: Civitas. En sentido contrario, J. C. BAYÓN MOHINO argumenta que la mera coincidencia de contenidos entre las normas morales y jurídicas no es base suficiente para justificar una obligación general de obediencia al Derecho, «porque como es obvio nada garantiza que lo que el Derecho exige sea de todos modos moralmente obligatorio, ni siempre ni tan siquiera generalmente» (La normatividad del Derecho, Centro de Estudios Constitucionales, 1991, p. 703)

${ }^{6} \mathrm{~J}$. C. BAYÓN, en sintonía con el punto de partida de este trabajo, afirma que la polémica sobre la obligación política sólo es sustantiva, y no meramente verbal, cuando lo que se discute es si entre el Derecho y la moral existe una conexión necesaria o por el contrario meramente contingente (ibídem, p. 698). Creo que la misma idea queda más claramente expresada si se enuncia a la inversa: en la discusión sobre si la identificación del Derecho depende enteramente de la comprobación de ciertos hechos sociales complejos, o si además requiere la intervención del juicio moral, los contendientes presuponen diferentes teorías de la obligación política. 
a una cualidad extrínseca a la realidad jurídica, estas teorías establecen únicamente una relación contingente entre las normas jurídicas y la obligación moral de cumplirlas. Desde su perspectiva, la justificación moral de la obediencia al sistema jurídico es una cuestión independiente de la identificación o existencia de las normas que lo constituyen. De ahí que sea el modelo de obligación política que mejor se corresponde con las concepciones iuspositivistas. Las distintas versiones del positivismo jurídico coinciden en afirmar la llamada «tesis de las fuentes sociales del Derecho», según la cual la identificación del Derecho válido de una comunidad política depende enteramente de una práctica social que determina en cada caso las fuentes o lugares de producción de las normas jurídicas ${ }^{7}$.

El modelo del deber natural de justicia, por el contrario, propone como condición de la obligatoriedad moral del Derecho una cualidad intrínseca a la naturaleza de las normas jurídicas. Como veremos, este modelo concibe la obligación política como un problema de filosofía moral y política instalado en el corazón mismo de la teoría general del Derecho. Por este motivo es el modelo que presuponen las teorías «interpretativas» del Derecho. Dicha denominación, a falta de otra mejor, remite a una forma de concebir el fenómeno jurídico en la que éste no existe únicamente en un sentido social o convencional, sino en el sentido más fuerte de tener fuerza normativa de carácter moral. Para estas teorías, el Derecho es una realidad que no puede identificarse sin hacer uso del juicio moral y la argumentación racional.

Finalmente, un escueto comentario sobre un problema íntimamente ligado a nuestra discusión. Me refiero a la legitimidad del poder político. En las teorías del consentimiento, la justificación de la obediencia al Derecho significa buscar el modo de hacer compatible la autonomía moral de los individuos con la sumisión a la autoridad política, es decir, con la heteronomía del Derecho. Los autores positivistas, al presuponer la corrección de este planteamiento, afrontan la obediencia al Derecho como un problema relativo a la legitimidad de la autoridad política. En este sentido, aunque nieguen la existencia de una obligación general de obedecer el Derecho por sí mismo, aún pueden afirmar dicha obligación a partir de la legitimidad democrática, siempre que la elaboración de las normas jurídicas cumpla ciertos requisitos de representación política que aseguren su justicia ${ }^{8}$. Como ha señalado L. GREEN, la legitimidad es una con-

${ }^{7}$ Dentro del actual positivismo jurídico se discute si la práctica social que determina qué es Derecho incluye no sólo hechos sociales, sino también principios morales —o, dicho de otro modo, si además de los criterios formales de órgano y procedimiento (relativos al origen o linaje de las normas), existen criterios materiales de validez normativa (que tienen que ver con los principios de justicia o valores morales sustantivos a los que las normas han de ajustarse para formar parte del sistema jurídico)—. Por mor de la claridad expositiva, no introduciré esta dificultad en mi argumento. No obstante, creo que tiene razón DwORKIN cuando afirma que la incorporación de criterios de validez vinculados a la moral desvirtúa la tesis de las fuentes sociales del Derecho («Thirty Years On», en Justice in Robes, Cambridge, Mass., Harvard University Press, 2006, pp. 188-198). En definitiva, dicha incorporación lleva consigo la posibilidad de identificar las normas jurídicas haciendo uso del juicio moral, lo cual no parece que sea compatible con la concepción del Derecho como práctica social. Por este motivo, centraré mi réplica al positivismo jurídico en la obra de J. RAZ, el cual limita los criterios de validez jurídica a los de carácter formal o de pedigree. Para un análisis detallado de esta polémica, $c f r$. R. EsCUDERO, 2004, Los calificativos del Positivismo Jurídico. El debate sobre la incorporación de la moral, Madrid: Civitas.

${ }^{8}$ Sirvan como ejemplos, $c f r$. H. KELSEN, 2002, Esencia y valor de la democracia, Granada: Comares; L. GREEN, The Authority of the State, op. cit.; F. LAPORTA, 1989, «Sobre la teoría de la democracia y el concepto de representación política: algunas propuestas para debate», Doxa, 6; R. SORIANO, 1993, Compendio de teoría general del Derecho, 2." ed., Barcelona: Ariel, 1993. 
dición necesaria de la obligación política, pero la misma circunstancia no se da en sentido contrario?.

Desde el modelo del deber natural, en cambio, el problema no se plantea en estos términos. La obligación política no consiste simplemente en la obediencia a las decisiones formales del poder político. Se trata más bien de guardar fidelidad a un esquema de principios morales que justifican las decisiones colectivas de una comunidad política determinada. Los autores que entienden el Derecho como interpretación presuponen este modelo de obligación política, puesto que para ellos la realidad jurídica no se reduce a las directivas e instrucciones del poder político, sino que incluye los principios que subyacen a esas decisiones en forma de justificación. Desde su punto de vista, la obligación moral constituye una condición «cuasi-necesaria» de la legitimidad política ${ }^{10}$.

\section{EL MODELO DEL DEBER NATURAL DE JUSTICIA}

La controversia en torno a la existencia de una obligación general de obediencia es inherente a la práctica de una democracia liberal ${ }^{11}$. La filosofía política moderna, encargada de justificar racionalmente esa práctica, dio por supuesto desde sus orígenes que el ser humano no está subordinado por naturaleza a autoridad alguna, y que, por tanto, el orden social ha de tener en cuenta necesariamente el punto de vista de los individuos. En palabras de J. RAWLS, los ciudadanos de un régimen constitucional «se consideran a sí mismos como fuentes auto-originantes de pretensiones válidas» ${ }^{12}$, lo cual implica que se ven a sí mismos como seres libres para actuar en su propio interés; cada uno de ellos puede derivar sus pretensiones a partir de sus propios fines y proyectos, sin tener que respaldar tales exigencias en deberes u obligaciones previos hacia la sociedad u otras personas. En estas condiciones, la justificación de la obligación política no puede limitarse a señalar directamente las ventajas de la cooperación social

${ }^{9}$ L. GREEN, 2002, «Law and Obligation», en The Oxford Handbook of Jurisprudence E Philosophy of Law, Oxford: Oxford University Press, p. 522. En el mismo sentido, R. SARTORIUS, 1981, «Political Authority and Political Obligation», Virginia Law Review, 67, 3; y K. GreENAWALt, 1987, «Legitimate Authority and the Duty to Obey», en Conflicts of Law and Morality, Oxford: Oxford University Press. Esta no es, sin embargo, una postura unánime dentro del positivismo jurídico. Como veremos más adelante, RAZ considera que la legitimidad política y el deber de obediencia son dos caras de la misma moneda. Según este autor, la falta de una obligación general de obediencia es reflejo de la legitimidad incompleta del Estado, incluso en una democracia razonablemente justa.

${ }^{10}$ R. DwORKIN, 1986, Law's Empire, London: Fontana Press, p. 191.

${ }^{11}$ En la mayor parte de las filosofías políticas premodernas, la sumisión al poder se consideraba un deber inexcusable en la medida en que sus directivas remitían a un «orden natural» en el que todos los entes tenían asignados su lugar y su función. En la medida en que el orden social se adecuaba correctamente a dicho orden, los individuos debían obedecer las leyes positivas, puesto que de este modo no sólo cumplían con los requerimientos de la justicia, sino que al mismo tiempo mantenían las condiciones necesarias para su felicidad - entendida ésta como el desarrollo de las facultades naturales-. El cuestionamiento de ese supuesto orden natural, debido especialmente al avance de la ciencia moderna, supuso la correspondiente desaparición de la coherencia entre los intereses general y particular que dicho orden garantizaba a priori. Cfr. E. SERRANO, 2004 La insociable sociabilidad. El lugar y la función del derecho y la politica en la filosofía práctica de Kant, Barcelona: Anthropos.

12 1986, «El constructivismo kantiano en la teoría moral», en Justicia como Equidad, Materiales para una teoría de la justicia, Madrid: Tecnos (trad. esp., M. A. Rodilla), p. 162. 
en la promoción del interés general; por el contrario, tiene que conciliar esas ventajas con el interés esencial que posee todo ciudadano en no obedecer otra voluntad distinta de la suya.

Las primeras teorías políticas de la Modernidad emplearon el consentimiento, o la aceptación voluntaria, como el mejor recurso para justificar las exigencias de un orden social basado en la libertad de los individuos. Según los contractualistas de los siglos XVII y XVIII, la búsqueda del interés general logra conciliarse con el respeto a la libertad individual cuando los términos de la asociación política son racionalmente acordados o, al menos, voluntariamente aceptados por todos sus miembros. Este enfoque, al que denominaremos el «modelo de la autonomía social» ${ }^{13}$, se ha usado abundantemente para justificar la obligación de cumplir el Derecho de una sociedad democrática ${ }^{14}$. Sin embargo, sus exigencias de participación popular en la formación de la voluntad política hacen que sea un modelo que difícilmente puede servir de base para justificar la obligación de obedecer el Derecho en las democracias realmente existentes ${ }^{15}$. Sea como fuere, lo que aquí nos interesa destacar es que dicho enfoque no permite justificar la obligación de obedecer el Derecho por ser Derecho ${ }^{16}$.

A la vista de estas dificultades, resulta tentador pensar que no es posible fundar la obligación política en la libre voluntad de los ciudadanos. Incluso podríamos llegar a concluir que los aspectos no voluntarios de la vida social —necesarios y deseables para la asociación de individuos racionales incapaces de actuar voluntariamente de forma cooperativa - socavan la posibilidad de la única justificación razonable de la obligación política. Parece como si estuviéramos forzados a elegir entre la postulación de al-

${ }^{13}$ La expresión procede de J. COHEN, 1986, «Reflections on Rousseau: Autonomy and Democracy», Philosopby and Public Affairs, 15, p. 279.

${ }_{14}$ En el panorama de la filosofía política contemporánea, y a modo de ejemplo, cabe citar a H. PITKIN, 1965, «Obligation and Consent», The American Political Science Review, 59; T. H. McPHERSON, 1967, Political Obligation, London: Routledge; P. SINGER, 1973, Democracy and Disobedience, Oxford: Oxford University Press; H. BERAN, 1987, The Consent Theory of Political Obligation, London: Croom Helm. Entre nosotros, Á. PELAYO GONZÁLEZ-TORRE, 1994, Consentimiento, democracia y obligación política, Madrid: Colex.

${ }^{15}$ C. PATEMAN, por ejemplo, afirma que la justificación de la obligación política sólo podrá tener lugar en una democracia «directa o participativa» (The Problem of Political Obligation, NJ, John Wiley \& Sons Ltd., 1979 , p. 18). Otros defensores del modelo de la autonomía social proponen la asimilación de las exigencias del «diálogo ideal intersubjetivo» en el funcionamiento real de las democracias como una condición necesaria para la legitimación del ejercicio del poder político y, como consecuencia, para la justificación de la obligación política. Cfr. J. Habermas, 1998, Facticidad y validez, Madrid: Trotta; A. CorTINA, 1985, «La justificación ética del Derecho como tarea prioritaria de la filosofía política. Una discusión desde John Rawls», Doxa, 2; R. Asís, 1991, Deberes y obligaciones en la Constitución, Madrid: Centro de Estudios Constitucionales; R. HERRANZ, 1994, «La justificación de la democracia y la obligación moral de obedecer el Derecho», Derechos y Libertades. Revista del Instituto Bartolomé de las Casas, 2.

16 Algo similar ocurre con la otra versión de la adquisición voluntaria: el principio de la equidad, o del fair play — cuyos más conocidos desarrollos están en H. L. A. HART, 1995 «Are There Any Natural Rights?», Philosophical Review 64; y J. RAWLS, 1999, «Legal Obligation and the Duty of Fair Play», en Collected Papers, ed. Samuel Freeman, Cambridge: Mass., Harvard University Press-. Según este principio, la obligación política se presenta como una obligación de equidad entre los miembros participantes de un esquema de cooperación mutuamente ventajoso. Sin embargo, este principio no es capaz de explicar por qué se deben considerar obligados a cooperar aquellos otros miembros de la comunidad que no han aceptado, ni expresa ni tácitamente, los beneficios de la cooperación —es decir, aquellos que no pueden ser llamados propiamente «participantes» en la empresa cooperativa-. Las ventajas que proporciona un Estado de Derecho pueden ser consideradas, en efecto, como un producto de la cooperación social, pero es evidente que la mayoría de los ciudadanos se benefician de ellas sin haberlas aceptado voluntariamente ( $c f r$. R. NozICK, 1974, Anarchy, State, and Utopia, Oxford: Blackwell; A. J. Simmons, Moral Principles and Political Obligation, op. cit.) 
gún tipo ideal de «gobierno por consentimiento» (o de «esquema cooperativo voluntario») y la pura negación de la autoridad moral del Derecho. Sin embargo, existe aún una tercera posibilidad: la idea del «deber natural». Como ha señalado J. WALDRON, resulta extraño el escaso interés que despierta esta noción, habida cuenta del tipo de relación moral que mantenemos con el Derecho. Aunque son pocos los ciudadanos que obedecen todas las normas en todo momento, los que reconocen la existencia de un requisito moral de obediencia parten de la convicción de que las normas jurídicas representan las demandas justas de la vida social, cuyo carácter imperativo no puede depender de ninguna circunstancia contingente como el consentimiento ${ }^{17}$.

Con vistas al argumento que vamos a desplegar aquí, lo decisivo es que el deber natural implica un modo «objetivo» de explicar cómo el Derecho justo actualiza o hace real la libertad individual. A diferencia de lo que ocurre en el modelo de la autonomía social, donde dicha realización depende de la aceptación voluntaria de los principios de justicia por parte de los ciudadanos - de modo que, en última instancia, la obediencia al Derecho implica cumplir las normas que ellos mismos se han dado-, en el modelo del deber natural los ciudadanos son libres al obedecer las directivas de un Estado globalmente justo porque con ello garantizan las condiciones sociales que les permiten perseguir sus propios fines con independencia de cualquier otra voluntad distinta de la suya ${ }^{18}$. En este punto, lo que nos interesa no es tanto la diferencia en las concepciones de la libertad que emplean ambos modelos, como el hecho de que cada uno subraye una forma peculiar de vincular el Derecho y la libertad. En el primer caso, la obediencia al Derecho es una forma de relacionarse con el orden social que supone en sí misma una expresión de libertad; en el segundo caso, la obediencia al Derecho implica la posibilidad de ejercer una voluntad independiente ${ }^{19}$.

El contraste entre estos dos modelos puede apreciarse, si bien de forma implícita, en El Contrato Social (1762) de Jean Jacques Rousseau ${ }^{20}$. Este texto es, como se sabe, una de las más encendidas defensas del modelo de la autonomía social. La re-

17 1990, «Special Ties and Natural Duties», Philosophy \& Public Affairs, 22, p. 3.

${ }_{18}$ Con objeto de resaltar lo que aquí se quiere decir, el texto no hace referencia al principio de la equidad. Sin embargo, dado que presupone la adquisición voluntaria de los beneficios sociales, este principio acarrea los mismos defectos que lleva consigo el consentimiento.

19 Algunos autores combinan ambos modelos en una sola teoría. Cfr. E. FERNÁNDEZ, La obediencia al Derecho, op. cit.; D. D. RAPHAEL, 1976, Problems of Political Philosophy, London: The Macmillan Press; G. KLOSKO, 2004, «Multiple Principles of Political Obligation», Political Theory, 32, 6.

Sin duda, como se verá más adelante, los dos modelos son perfectamente compatibles, y resultan complementarios en la justificación de un régimen constitucional. Sin embargo, cada uno de ellos es capaz de generar diferentes argumentos justificativos, lo cual es especialmente importante cuando no se discute dicho régimen en su totalidad, sino que se trata de justificar únicamente un aspecto concreto del mismo.

${ }^{20}$ La razón para empezar nuestro argumento con ROUSSEAU radica en que este autor puede considerarse, si hacemos caso a HEGEL, como el primer pensador que fundamenta la filosofía política en el principio de la «voluntad libre» [Filosofía del Derecho (1821), Barcelona: Edhasa, 1999, trad. esp., J. L. VermaL, p. 372]. Para Rousseau, al contrario que para LOCKE, el papel del Estado con respecto a la libertad no se reduce simplemente a preservar y promover una libertad que los individuos pueden disfrutar al margen de su condición de ciudadanos de una comunidad política. Según el ginebrino, los seres humanos nacen libres, pero sólo pueden actualizar o hacer real su libertad dentro de los confines del Estado. No obstante, como ya indiqué al inicio, este trabajo recurre a la historia de las ideas con el único propósito de rescatar los materiales que permiten construir un argumento en pro de la obligación política. Para un desarrollo histórico de la idea de libertad «negativa» como libertad política, $c f r$. Q. SKINNER, «The Idea of Negative Liberty: Philosophical and Historical Perspectives», en R. RORTY, J. B. SchneEwind y Q. Skinner (eds.), 1984, Philosophy in History, Cambridge: Cambridge University Press. 
conciliación del interés general y la libertad individual se alcanza, según ROUSSEAU, cuando todos los individuos se identifican conscientemente con la voluntad general, lo cual no sólo requiere que todos alcancen un entendimiento compartido del bien común, sino además que cada uno esté dispuesto a considerar ese bien como su interés más auténtico. Con todo, el libro de Rousseau contiene un par de pasajes que carecen de sentido desde el enfoque del autogobierno. El primero es donde dice que «quien se niegue a obedecer a la voluntad general será obligado por todo el cuerpo [político], lo que no significa sino que se le obligará a ser libre» ${ }^{21}$. El segundo texto se encuentra en la discusión sobre los procedimientos de votación en las asambleas del pueblo. Allí, Rousseau afirma que los ciudadanos de un Estado bien constituido son libres, incluso cuando se les exige que se sometan a leyes particulares que no se ajustan a sus propias opiniones de lo que prescribe el bien común ${ }^{22}$. En ambos casos, la idea parece ser que los ciudadanos alcanzan la libertad cuando están sujetos a la voluntad general, con independencia de que la reconozcan o no conscientemente como la suya propia. En este sentido, que la voluntad general sea la voluntad (profunda o verdadera) de cada individuo no depende de que los individuos reconozcan este hecho como tal.

La clave para entender esta forma de identificación «objetiva» entre las voluntades general y particular nos la da el propio ROUSSEAU al añadir a continuación del «se les obligará a ser libres»: «porque esto [la estipulación de que los individuos sean constreñidos a seguir la voluntad general] es la condición que, al entregarse cada ciudadano a la patria, le protege contra toda dependencia personal $\gg^{23}$. Para ROUSSEAU, la dependencia respecto de los otros (tanto económica como psicológica) representa el mayor obstáculo para la realización de la libertad. Sin embargo, la estrategia del filósofo no consiste en tratar de erradicar la interdependencia de los seres humanos - algo impracticable dada nuestra naturaleza social—, sino más bien en perseguir su reestructuración, de modo que deje de implicar el sometimiento a la voluntad de los demás. La solución que sugiere ROUSSEAU es transformar la dependencia respecto a personas individuales en una dependencia respecto a la comunidad como un todo. En este sentido, la voluntad general de ROUSSEAU implica el conjunto de instituciones que recomponen la dependencia personal, con la eliminación, o al menos la reducción significativa, de sus consecuencias dañinas para la libertad. En el Estado ético rousseauniano, cada ciudadano se «protege contra toda dependencia personal» mediante la obediencia (forzada o voluntaria) a las instituciones de la voluntad general ${ }^{24}$.

Desde esta perspectiva, la voluntad general no significa la realización de la libertad moral (o de la autonomía social), sino una precondición de la «libertad civil» ${ }^{25}$. Como señala F. NEUHOUSER, las instituciones de la voluntad general garantizan a cada ciudadano «no sólo el derecho abstracto, sino la posibilidad real de actuar sin estar restringido por la voluntad de los demás dentro de una esfera de actividad externa a los inte-

${ }^{21}$ 1992, El contrato social o Principios de derecho político, Madrid: Tecnos (trad. esp., M. J. Villaverde), p. 19.

${ }^{22}$ Ibídem, p. 107.

${ }^{23}$ Ibidem, p. 19.

${ }^{24}$ Cfr. F. Neuhouser, 1993 «Freedom, Dependence and the General Will», The Philosophical Review, 102,3

${ }^{25}$ El contrato social, op. cit., p. 19. 
reses vitales de la comunidad» ${ }^{26}$. En este sentido, que la voluntad general constituya además la voluntad de cada individuo no depende de una cualidad subjetiva de las voluntades individuales, sino de un rasgo objetivo de la voluntad general misma - a saber, de que su querer tiene por objeto las condiciones que hacen posible la liberación de los individuos respecto de las voluntades arbitrarias de los demás-. El sometimiento a la voluntad general se puede concebir, por tanto, como un deber natural (incondicionado). No sólo su existencia acontece al margen de la voluntad de los ciudadanos, sino que además éstos no pueden zafarse de su cumplimiento sin dejar de ser libres. Cuando alguien «elige» actuar de un modo contrario a lo que exige la voluntad general, impide la realización de su propia libertad (y la de sus conciudadanos), por lo que no puede considerarse que esté haciendo «su» voluntad.

El mismo argumento lo encontramos explícitamente en la filosofía del Derecho de I. KANT —o, lo que es lo mismo, en la primera parte de La metafísica de las costumbres (1797)—. La forma en que este autor concibe las relaciones entre la moral y el Derecho representa, aún con mayor dramatismo que en el caso de Rousseau, la tensión entre el enfoque de la autonomía y la perspectiva del «obligar a ser libres». Numerosos autores han puesto de relieve la contraposición entre la ética kantiana, basada en el valor supremo de la autonomía, y el carácter radicalmente heterónomo con que KANT describe el Derecho ${ }^{27}$. Sin embargo, esta oposición desaparece cuando se distinguen los ámbitos propios de, por un lado, la libertad «trascendental» o autonomía en abstracto, y, por otro, la libertad externa — es decir, la libertad en su sentido de «independencia con respecto al arbitrio constrictivo de otro» ${ }^{28}$ - El ámbito de la libertad trascendental es, principalmente, la conciencia individual; sólo como «idea pura práctica» se extiende también a la comunidad ideal del «reino de los fines». Cada miembro del reino de los fines asume por sí mismo una ley que él se da, y que es, a la vez, la ley que todos los demás miembros se imponen libremente. En el ámbito de la libertad externa, sin embargo, se trata de hacer posible la libre determinación de los hombres en la interdependencia del mundo social, donde las acciones de los individuos han de conjugarse forzosamente entre sí. Con este objetivo, dice KANT, el Estado jurídico o civil establece «el conjunto de condiciones bajo las cuales el arbitrio del uno puede conciliarse con el arbitrio del otro, según una ley general de libertad» ${ }^{29}$.

Para KANT, por tanto, el Derecho constituye la condición de la libertad en la coexistencia, es decir, «la condición de la autonomía en el mundo de las relaciones humanas» ${ }^{30}$. El Derecho, entendido como «ley general de libertad», delimita para todos los ciudadanos una esfera igual de acción independiente. Por esta razón, la imposición coactiva de su obediencia no daña la libertad, pues todo lo que se opone al Derecho es un impedimento de la libertad que debe ser eliminado «en virtud del principio de contradicción» ${ }^{31}$. Si un cierto uso de la libertad es un obstáculo para la realización de

${ }^{26}$ «Freedom, Dependence and the General Will», op. cit., p. 392.

${ }^{27}$ Sirva como ejemplo el texto de I. BERLIN, 1988, «Dos conceptos de libertad», en Cuatro ensayos sobre la libertad, Madrid: Alianza.

${ }^{28}$ I. KANT, 1989, La metafísica de las costumbres, Madrid: Tecnos (trad. esp., A. Cortina y J. Conill), p. 48.

${ }^{29}$ Ibidem, p. 39.

${ }^{30}$ F. GONZÁLEZ VICÉN, 1977, «La filosofía del Estado en Kant», en I. KANT, Introducción a la teoría del Derecho, Madrid: Marcial Pons, p. 72.

${ }^{31}$ La metafísica de las costumbres, op. cit., p. 41. 
ésta según leyes generales, dice KANT, «entonces la coacción que se le opone, en tanto que obstáculo frente a lo que obstaculiza la libertad, concuerda con la libertad según leyes universales» ${ }^{32}$. Por tanto, no es la aceptación voluntaria, sino un rasgo objetivo del Estado de Derecho, lo que hace obligatoria la obediencia a las normas y principios jurídicos. Para KanT, existe un deber moral de obedecer el Derecho por ser Derecho, es decir, por ser un orden general y cierto de convivencia que posibilita el ejercicio de la libertad trascendental en el mundo sensible. La obediencia al Derecho no sólo acontece cuando sus normas son justas desde el punto de vista de la conciencia individual; por el contrario, se da siempre que el Derecho es Derecho, esto es, siempre que pretende asegurar mediante reglas abstractas un ámbito de acción dentro del cual los individuos pueden hacer realidad la exigencia de autonomía dirigida a su ser individual.

En la filosofía política contemporánea, el valedor más conocido del deber natural de justicia es J. RAWLS, especialmente en Una teoría de la justicia. Este texto pretende ser heredero de la tradición contractual, por lo que la autonomía social es sin duda el modelo que inspira el conjunto de la obra. Sin embargo, es posible apreciar una relación objetiva entre la libertad individual y los principios de justicia allí donde el autor defiende su concepción de la «justicia como equidad» frente al utilitarismo. En la teoría utilitaria, la sociedad maximiza la satisfacción agregada de los intereses que los individuos han elegido previamente y sin restricción alguna. En la «justicia como equidad», por el contrario, los ciudadanos «acuerdan anticipadamente los principios por los cuales tienen que fijarse sus pretensiones mutuas» ${ }^{33}$. Los principios de la justicia reciben, pues, «primacía absoluta», de tal modo que los ciudadanos diseñan y persiguen sus concepciones del bien a partir de ellos. Este «acuerdo previo» sobre los principios de la justicia implica un tipo de congruencia entre la justicia y el bien que no depende de la aceptación voluntaria de los ciudadanos. El sentido de la justicia puede considerarse bueno para los individuos, incluso aunque ellos no lo reconozcan conscientemente como tal, puesto que al actuar bajo sus dictados sostienen las condiciones necesarias para la libre elección de sus proyectos de vida. Los principios constriñen o delimitan «desde el principio» las concepciones del bien de los ciudadanos ${ }^{34}$. Aquellos individuos que no ajustan el contenido y la persecución de sus concepciones del bien a los reclamos de la justicia, actúan de manera inconsistente con lo que hace posible su propia libertad de decisión (junto con la de sus asociados), y, por tanto, no pueden ser considerados como electores de «sus» concepciones del bien.

32 Ibidem, p. 40.

33 J. Rawls, 1971, A Theory of Justice, Cambridge; Mass., Harvard University Press (trad. esp., M. D. González, México, Fondo de Cultura Económica, 1978), p. 565. Las citas de este libro son traducciones directas de la versión original.

34 RAWLS subraya este punto en numerosas partes del libro. Así, por ejemplo, afirma que los principios de justicia, y más en concreto, su realización en formas sociales, «definen los límites dentro de los cuales tienen lugar nuestras deliberaciones» (ibídem, p. 563); «ponen límites sobre qué satisfacciones tienen valor; imponen restricciones sobre cuáles son las concepciones razonables del bien» (ibidem, p. 31); «restringen el contenido de los proyectos [de vida], los fines que persiguen y los medios que usan» (ibídem, p. 449). Todos estos textos ponen de manifiesto que, para el RAWLs de Una teoría de la justicia, no es posible ejercer la capacidad de formar y perseguir una concepción del bien al margen de los límites de la justicia. Fuera de una sociedad bien ordenada, el bien de los individuos depende únicamente de las circunstancias arbitrarias, sociales o naturales, en que les ha tocado nacer y vivir. Dicho de otro modo, sin justicia no hay lugar para la autoridad de la reflexión individual sobre la formación de la personalidad moral. 
De lo dicho hasta aquí no se sigue, sin embargo, la existencia de incompatibilidad alguna entre ambos modelos. La libertad moral (estar sujeto únicamente a las normas que uno se auto-impone) y la libertad civil (no depender de las constricciones impuestas por la voluntad de otros) no son concepciones rivales, sino formas diferentes y complementarias de entender la condición básica de la libertad —esto es, la condición de no obedecer otra voluntad distinta de la propia de cada uno-- Por ello, no hay problema en afirmar simultáneamente los dos modelos de la obligación política. Mientras el primero hace coincidir la esfera de la libertad moral con el dominio del Derecho mismo (mediante el uso de procedimientos democráticos de formación de la voluntad política), el segundo trata de proteger una esfera de acción libre que sólo puede definirse negativamente (como la condición de no estar constreñido a obedecer las voluntades particulares de otros individuos).

Sin embargo, los dos modelos entran en colisión cuando tratan de explicar cómo se realiza la libertad en un Estado globalmente justo —es decir, cómo la sumisión al Derecho justo consigue que los ciudadanos obedezcan únicamente su propia voluntad y por tanto sean libres- - En el caso de la autonomía social, se recurre a la suposición de una relación subjetiva de los ciudadanos con el Derecho, relación que consiste en la afirmación consciente de los principios que informan el sistema jurídico en su conjunto. En el caso del deber natural, por el contrario, la explicación no depende de una cualidad subjetiva de la voluntad de los individuos, sino de un rasgo objetivo del Derecho justo - su capacidad para garantizar las condiciones que liberan a los individuos de la sujeción a las voluntades arbitrarias de otros-. La tensión entre estas dos concepciones de la libertad política se manifiesta en aquellos casos en que los ciudadanos de una sociedad bien ordenada no afirman conscientemente los principios que les gobiernan, principios que, desde el punto de vista objetivo del deber natural, son necesarios para su libertad.

Lo importante para nuestro argumento es que el modelo del deber natural es el único que consigue explicar la obligatoriedad, así como el carácter coercitivo, del Derecho. No obstante, aunque las instituciones políticas logren satisfacer las exigencias de la justicia, estableciendo así las condiciones objetivas que permiten a los ciudadanos actuar libremente, es obvio que la libertad de éstos no será plena mientras ellos mismos no se identifiquen conscientemente con dichos principios. Por eso, aunque el deber natural sea el único modelo relevante para la justificación moral de la obediencia al Derecho globalmente justo, de ahí no se deduce que debamos ignorar la importante función que cumple la autonomía social en nuestra comprensión de la libertad política.

\section{DEBER DE JUSTICIA Y PLURALISMO RAZONABLE}

En Una teoría de la justicia, RAWLS reconoce que ni la aceptación voluntaria, ni el principio del fair play, pueden justificar una obligación general de obediencia a los principios de justicia ${ }^{35}$. En su lugar, el autor afirma que esta obligación surge de un deber

${ }^{35}$ A Theory of Justice, op. cit., pp. 114, 116. Sobre el principio de la equidad o del fair play, ver nota 16. 
moral anterior a cualquier tipo de acuerdo voluntario: el deber de tratar a las personas como iguales ${ }^{36}$. Para RAWLS, los principios que subyacen a un régimen constitucional moderno constituyen la expresión sustantiva de nuestro deber moral, formal y abstracto, de tratar a las personas como iguales. Dicho de otro modo, la normatividad de un Estado de Derecho deriva del deber «natural» de fomentar aquellas instituciones sociales que reconocen y promueven nuestra igualdad moral.

En la tercera parte del libro, sin embargo, RAwLS se centra en el modelo de la autonomía social para explicar por qué debemos preocuparnos por los reclamos de la justicia. Desde la perspectiva de este modelo, el autor concluye afirmando que la normatividad de «nuestro» sentido de la justicia —es decir, la fuerza normativa de los principios que guían el razonamiento y la discusión sobre cuestiones de moralidad política en el seno de nuestras sociedades democráticas - tiene su origen, no en el deber moral de igualdad de trato, sino en el deseo de realizar nuestra naturaleza como seres morales libres e iguales ${ }^{37}$. Vistas así las cosas, la obediencia a los principios de justicia no tiene por objeto mantener las condiciones que hacen posible el ejercicio de una voluntad independiente; en su lugar, la obediencia misma se concibe como un acto de libertad. Lo cual requiere, para llevarse a efecto, presuponer que los ciudadanos asumen la autonomía como un fin en sí mismo, un bien supremo que sólo pueden alcanzar sometiendo el resto de sus fines a las restricciones de la justicia.

Pero semejante presupuesto no es compatible con una sociedad democrática, ni siquiera en las mejores condiciones previsibles. Así lo reconoce el propio RAWLS en el prólogo a su Liberalismo político. El desacuerdo en torno a las concepciones del bien es el resultado inevitable del uso libre de la razón en condiciones democráticas, por lo que la legitimidad política en tales condiciones no puede ignorar el hecho del pluralismo moral ${ }^{38}$. No obstante, la solución del «liberalismo político» se mantiene dentro del marco teórico de la autonomía social. Su estrategia se basa en hacer creíble la posibilidad de un acuerdo entre las distintas doctrinas comprehensivas razonables en torno a los principios de justicia — es decir, mostrar la posibilidad de un consenso «por superposición» (overlapping consensus) ${ }^{39}$ - Con este objetivo, RAWLS presenta los principios desde una perspectiva «política» que no se identifica con ninguna concepción del bien en particular, permitiendo así que el consenso dependa únicamente del hecho de que los ciudadanos deseen ser gobernados por principios que los demás miembros, movidos por una motivación semejante, puedan aceptar. La congruencia sustantiva de los principios y las concepciones del bien «se deja a los ciudadanos, individualmente —como parte de su libertad de conciencia $\longrightarrow{ }^{40}$.

${ }^{36}$ Ibidem, pp. 115-116. La base de dicha igualdad — es decir, «los rasgos de los seres humanos en virtud de los cuales han de ser tratados de acuerdo con los principios de la justicia»— no radica en ciertos «atributos naturales», sino en «la capacidad de personalidad moral» (ibidem, pp. 504-505), la cual, como mera potencialidad, es idéntica en todos los seres humanos. El ejercicio de esta capacidad nos permite identificar y perseguir lo que, tras la debida reflexión, nos parece una vida valiosa.

37 Ibidem, pp. 572, 574.

38 J. Rawls, 1993, Political Liberalism, New York: Columbia (trad. esp., A. Domènech, Barcelona, Crítica, 1996), pp. xviii-xxix. Las referencias a esta obra corresponden a la versión original.

39 En términos de T. NAGEL, la justicia como equidad de RAWLS deja de ser una «teoría del punto de vista común» para convertirse, predominantemente, en una «teoría de la convergencia» («Moral Conflict and Political Legitimacy», Philosophy \& Public Affairs, 16, 1987, pp. 218-219).

${ }^{40}$ Political Liberalism, op. cit., p. 140. 
Sin embargo, en una sociedad donde se garantiza el uso libre de la razón, es inevitable que exista un desacuerdo razonable tanto en relación a las concepciones del bien como en lo relativo a las concepciones de la justicia. Como han señalado diversos autores, no es posible separar la moralidad política como una subclase independiente del resto de la moralidad ${ }^{41}$. Por mucho que se adelgace el contenido moral del consenso, el modelo de la autonomía social no puede dejar de exigir a los ciudadanos la identificación con el bien común que persigue la voluntad general (o, en terminología rawlsiana, con el bien político que realizan los principios de justicia), así como la predisposición a priorizar ese bien sobre el resto de sus fines en caso de conflicto. La dificultad de semejante identificación unánime en un régimen constitucional me parece evidente, y es la razón última por la que no creo que se deba intentar basar la obligación política en la promesa del consenso ${ }^{42}$.

En el modelo del deber natural, por el contrario, la obligatoriedad del Derecho justo no depende de un acuerdo sobre los principios de justicia, por lo que no es necesario presuponer la identificación de los ciudadanos con ningún fin común. El objetivo que se persigue en este modelo es la realización de la libertad, pero no como un fin en sí mismo, sino como una capacidad que permite a los individuos vivir según sus propias convicciones acerca de lo que da valor a sus vidas. Es más, el logro de este objetivo depende de que los ciudadanos pongan entre paréntesis sus propias concepciones de la justicia, y ajusten sus fines y ambiciones a los principios que subyacen bajo el esquema constitucional de su comunidad política. Como señala KANT, la sumisión a la autoridad del Derecho es «en sí mismo un deber, e incluso la suprema condición formal de todos los demás deberes externos», pues nadie puede tener por garantizada su esfera de libertad si cada uno obedece las normas jurídicas únicamente cuando coinciden con su propia concepción de lo que es justo y bueno ${ }^{43}$. Para KanT, el desacuerdo moral es inevitable y, a falta de «una coacción externa legalmente pública», conduce irremisiblemente a un estado de arbitrariedad y violencia ${ }^{44}$.

La obligación de obedecer las directivas de un Estado de Derecho se basa, por tanto, en un valor ético: la integridad de la justicia, es decir, la aplicación, mediante el uso del poder coactivo del Estado, de una y la misma concepción de la justicia para todos los miembros de la comunidad. La integridad política significa igualdad ante la Ley, pero no únicamente en el sentido formal de que a todos se aplican las mismas normas jurídicas tal y como están escritas, sino en el sentido sustantivo de que todos, legisladores y ciudadanos, están sometidos a los mismos principios de justicia.

${ }^{41}$ Cfr. R. DwORKIN, 1990, «Foundations of Liberal Equality», The Tanner Lectures on Human Values, XI, University of Utah Press; T. MCCARTHY, 1994, «Kantian Constructivism and Reconstructivism: Rawls and Habermas in Dialogue», Ethics, 105, 1; M. SANDEL, 1998, «A Response to Political Liberalism», en Liberalism and the Limits of Justice, 2. ${ }^{a}$ ed., Cambridge: Cambridge University Press.

42 2008, He desarrollado con más detalle este argumento en «Objetividad, consenso y obligación política», Daimon, 43.

${ }^{43}$ I. KANT, 1986, En torno al tópico: «Tal vez eso sea correcto en teoría, pero no sirve para la práctica» [1793], Madrid: Tecnos (trad. esp., J. M. Palacios, M. F. Pérez López y R. Rodríguez Aramayo), p. 26.

${ }^{44}$ La metafísica de las costumbres, op. cit., p. 141. Para ver, en este punto, las coincidencias entre KANT y HobBes, cf. J. WALDRON, 1999, «Kant's positivism», en The Dignity of Legislation, Cambridge: Cambridge University Press. Por supuesto, WALDRON también desarrolla las diferencias que separan a ambos autores en cuanto a la explicación que cada uno ofrece del carácter inevitable del desacuerdo moral, así como de su inexorable final violento en ausencia de una autoridad coactiva. 
La distinción entre igualdad formal y «sustantiva» es una idea común entre los filósofos políticos. F. HAYEK, por ejemplo, la utiliza para señalar cómo la libertad individual depende esencialmente de la igualdad en el segundo sentido. «Cuando obedecemos las leyes», afirma HAYEK, «no estamos sujetos a la voluntad de otro hombre y por tanto somos libres», pero esto sólo es verdad, añade, cuando las «leyes» no son meras órdenes específicas emanadas de la autoridad legislativa, sino reglas caracterizadas por su generalidad e igualdad ${ }^{45}$. La misma idea es ampliamente desarrollada por R. DwORKIN, para quien la integridad de la justicia garantiza el valor fundamental de la igualdad de condición y respeto de todos los ciudadanos. En la sofisticada teoría de DwORKIN sobre los fundamentos del liberalismo, la igualdad es una idea inseparable de la libertad. El ideal del Estado de Derecho es, según este autor, un esquema neutral de distribución de bienes, oportunidades y libertades en el que todos los ciudadanos pueden perseguir libremente sus propias concepciones de la vida buena, sin que ninguno de ellos pueda verse favorecido por ser más digno de consideración o por poseer una concepción del bien más noble que la de otros ${ }^{46}$.

DwORKIN considera la integridad, y no el consentimiento, como la condición que otorga legitimidad moral a la comunidad para ejercer el poder político e imponer obligaciones morales. Por este motivo, creo que su teoría de la obligación política debe ser incluida dentro del modelo del deber de justicia. No obstante, es cierto que DwORKIN define la obligación política como un tipo de obligación asociativa o comunitaria, como una obligación de solidaridad entre los miembros de una determinada comunidad, y que rechaza las teorías del deber natural de justicia por ser incapaces de explicar el carácter particular de este tipo de obligaciones ${ }^{47}$. A pesar de ello, hay buenas razones para respaldar la inclusión que aquí se defiende. Apuntaré las dos que considero más importantes. En primer lugar, el «deber natural» al que se remite DWORKIN es el que existe entre los miembros de una comunidad nacional, pero dicho deber sólo se hace efectivo en la medida en que esa comunidad se rige por el principio de la integridad de la justicia, lo cual lleva consigo una serie de condiciones independientes de las propiedades psicológicas de los asociados ${ }^{48}$. La obligación política no deriva, por tanto, de la identificación voluntaria de los ciudadanos con su comunidad. De hecho, nuestro autor describe el tipo de comunidad propio de la integridad política por contraste con la sociedad que corresponde al principio contractual (y al del fair play), y afirma que, mientras los miembros de este segundo tipo de comunidad no se consideran obligados por otras normas que las que han aceptado o negociado expresamente, los del primer tipo asumen que sus destinos están unidos por principios comunes, de tal modo que sus obligaciones políticas no proceden de su voluntad, sino del hecho de que su comunidad ha adoptado una Constitución que remite a un determinado esquema de principios morales ${ }^{49}$.

45 1960, The Constitution of Liberty, Chicago: The University of Chicago Press, p. 153.

46 1977, «What Rights do we Have?», en Taking Rights Seriously, Cambridge: Mass., Harvard University Press (trad. esp., M Guastavino, Barcelona: Ariel, 1984); 1985, «Liberalism», en A Matter of Principle, Oxford: Oxford University Press; «Integrity», en Law's Empire, op. cit.

${ }^{47}$ Law's Empire, op. cit., pp. 190-207.

${ }^{48}$ Ibídem, pp. 198-201. Las obligaciones asociativas, además de tener que ser especiales y personales, han de surgir de una preocupación general por el bienestar de los otros miembros del grupo, y de una preocupación igual por todos ellos.

${ }^{49}$ Ibídem, pp. 209-211. 
En segundo lugar, como ha puntualizado WALDRON, los principios que dan lugar al deber natural de justicia pueden ser perfectamente sensibles al tipo de comunidad política al que van dirigidos ${ }^{50}$. La teoría de la justicia de RAWLS, por ejemplo, se presenta como una concepción aplicable a una comunidad «aislada» de otras comunidades ${ }^{51}$. Es más, el argumento del deber natural aconseja restringir, al menos en primera instancia, el ámbito de aplicación de los principios a las relaciones humanas más cercanas. En efecto, si el marco legal es el instrumento que sirve para garantizar a los individuos una esfera de acción independiente, es obvio que su establecimiento resultará más urgente en la esfera de interacción más inmediata, pues es ahí donde se darán con mayor probabilidad situaciones de dependencia. En definitiva, el deber natural de justicia no es más que la aplicación, en el plano social, del deber moral abstracto de tratar a las personas como iguales, y es obvio que la comunidad nacional es el primer contexto social en el que tiene lugar dicho deber. No obstante, hablar de un deber natural de justicia, en lugar de obligaciones asociativas, tiene la ventaja de no restringir de entrada el posible ámbito de aplicación de los principios de justicia. A medida que se expanda la esfera de la interacción humana, deberá extenderse, o en su caso replantearse, el ámbito de aplicación del marco legal, de acuerdo con el mismo principio del deber natural de justicia.

\section{INTEGRIDAD POLÍTICA E IDENTIFICACIÓN DEL DERECHO}

El argumento que hemos desarrollado hasta aquí pretende establecer una obligación moral abstracta de obediencia al Derecho. Su propósito es justificar la autoridad del Derecho para imponer deberes morales, cualesquiera que sean, y para hacerlos cumplir con la amenaza de la fuerza. No se trata, por tanto, de obtener la generalidad de la obligación política agregando todas las obligaciones específicas de obediencia a cada una de las directivas de un sistema jurídico. Al contrario, el modelo del deber natural de justicia propone un tipo de justificación que discurre, por así decirlo, «de arriba abajo» ${ }^{52}$ : se parte de unos principios de justicia que sirven de base a una estructura constitucional, y a partir de ahí se afirma la obligatoriedad de todas las normas que componen el sistema jurídico presidido por dichos principios. En un régimen democrático de Derecho, todos (legisladores, jueces y ciudadanos) deben justificar las instituciones y decisiones políticas apelando únicamente a la concepción de la justicia que encarna la Constitución. Ésta contiene los principios y procedimientos que orientan la producción legislativa hacia dicho estándar de justicia. Sin embargo, esto no garantiza que todas las normas que se promulguen dentro de este marco sean perfectamente justas. En palabras de RAWLS, se trata de un caso de «justicia procedimental imperfecta» ${ }^{53}$. Siempre que la injusticia no exceda ciertos límites, cada ciudadano de un régimen constitucio-

${ }^{50}$ WALDRON denomina a los principios de justicia que tienen un ámbito determinado de aplicación «principios de alcance limitado» (range-limited principles), y emplea para su justificación la idea kantiana del Estado de Derecho como resolución de conflictos entre intereses que convergen sobre los mismos recursos ( $«$ Special Ties and Natural Duties», Philosophy \& Public Affairs, 2, 1993).

${ }^{51}$ A Theory of Justice, op. cit., p. 8.

52 S. PERRY, 2005, «Law and Obligation», The American Journal of Jurisprudence, 50, p. 270.

53 A Theory of Justice, op. cit., p. 198. 
nal tiene un deber natural de obedecer el Derecho, incluso cuando éste cometa errores sobre la justicia ${ }^{54}$.

El modelo del deber natural invoca la integridad de la justicia como un criterio intrínseco a la realidad jurídica misma. Dicho criterio permite justificar la obligación moral de obedecer las normas y principios de un sistema jurídico precisamente porque forman parte de ese sistema. Se deduce de este modelo, por tanto, una concepción del fenómeno jurídico en la que éste no puede identificarse con independencia de su obligatoriedad moral. De ahí que se trate del modelo de obligación política que presuponen las teorías del Derecho como interpretación. Estas teorías afirman que la realidad jurídica del Derecho válido depende, en parte, de su justificación moral; dicho de otro modo, que la identificación de las normas y principios jurídicos válidos de una comunidad política no depende exclusivamente de las prácticas sociales, sino también de la argumentación y el juicio moral.

DwORKIN, el autor quizá más representativo de este tipo de teorías, defiende una «lectura moral» del Estado de Derecho, según la cual los preceptos constitucionales invocan principios de justicia que exigen el ejercicio del juicio moral para su aplicación ${ }^{55}$. Esto implica que la «validez formal» o existencia de la norma dentro del ordenamiento jurídico depende, en parte, de la justificación de su «validez normativa» ${ }^{56}$. Dicho en términos de DwORKIN, las condiciones de verdad de las proposiciones jurídicas (the ground of law) incluyen la condición de la integridad que fundamenta su fuerza obligatoria (the force of law $)^{57}$. En una proposición del tipo «A forma parte del sistema jurídico (de una determinada jurisdicción)» — donde A es una proposición normativa que establece que alguna persona o grupo de personas tiene cierta obligación, derecho, permiso, responsabilidad o poder-, las condiciones de verdad de dicha proposición incluyen la de que A concuerde con la estructura constitucional de ese sistema, es decir, la condición que hace que A sea moralmente obligatoria. En definitiva, como señala S. PERRY, DWORKIN no afronta el problema de la obligación política suponiendo que el contenido del Derecho es algo ya dado, una realidad que podemos identificar mediante un criterio independiente de su obligatoriedad; al contrario, para él la teoría de la obligación política «es una parte integral de la teoría sobre los fundamentos del Derecho (grounds of law), y por tanto tiene un efecto en el contenido del Derecho» ${ }^{58}$.

${ }^{54}$ De aquí se deduce que, en el modelo del deber natural, sólo se considera obligatorio aquellas partes del Derecho que tienen que ver con los principios de justicia. Esto puede parecer demasiado restringido (L. GREEN, «Law and Obligation», op. cit., p. 539). Sin embargo, la conexión con la justicia no predetermina el ámbito material de regulación jurídica sobre el que existe la obligación moral de obediencia. Cualquier aspecto de la vida social puede ser objeto de regulación a partir de los principios de justicia, con tal de que se compruebe que en dicho ámbito está en juego la igualdad de derechos y oportunidades de los ciudadanos. En definitiva, el modelo del deber natural presupone que todas las funciones de un Estado de Derecho tienen como fin último la búsqueda y mantenimiento de un régimen jurídico razonablemente justo.

${ }_{55}$ R. Dworkin, 1996, Freedom's Law. The Moral Reading of the American Constitution, Cambridge: Mass., Harvard University Press.

${ }_{56}$ En la explicación del texto hago uso de dos de las acepciones o aspectos de la validez jurídica que distingue R. SORIANO en su Compendio de Teoría General del Derecho, op. cit., p. 94.

${ }^{57}$ La distinción entre grounds y force del Derecho aparece en Law's Empire, op. cit., pp. 108-113.

58 2006, «Associative Obligations and the Obligation to Obey the Law», en Exploring Law's Empire: The Jurisprudence of Ronald Dworkin, Oxford: Oxford University Press, p. 186. 
La conexión entre el deber natural de justicia y la interpretación pone en evidencia que la afirmación de una obligación general de obediencia no es incompatible con el reconocimiento de una amplia legitimidad moral a la desobediencia civil. Para una teoría interpretativa del Derecho como la de DwORKIN, la obligación política significa «la fidelidad a un esquema de principios que cada ciudadano tiene la responsabilidad de identificar, en última instancia por sí mismo, como el esquema de su comunidad» ${ }^{59}$. La obligación política es, según esto, un deber que remite la decisión última sobre la obligatoriedad de las normas a la conciencia individual. Sin embargo, como vengo insistiendo, esta «actitud protestante» frente al Derecho no debe confundirse con un enfoque individualista en virtud del cual las normas sólo son obligatorias cuando su contenido coincide con los dictados de la conciencia moral de los individuos ${ }^{60}$. En una comunidad donde rige el principio de la integridad política, los ciudadanos aceptan que las normas jurídicas explícitas de su comunidad presuponen un esquema común de justicia del que deriva su fuerza normativa; asumen que viven bajo el gobierno de unos principios comunes de justicia que justifican las decisiones políticas formales de su comunidad. La obediencia al Derecho depende de que las normas concuerden con los principios que su comunidad ha adoptado históricamente, no de que se ajusten a los principios que el individuo elegiría si la decisión dependiese enteramente de él ${ }^{61}$. La exigencia moral de desobediencia surge, de acuerdo con esta teoría, no cuando la norma se aparta de lo que cada uno cree que es justo, sino cuando el individuo cree en conciencia que la norma no es coherente con el esquema común de justicia que subyace a la Constitución ${ }^{62}$.

Hasta aquí el modelo del deber natural de justicia, y su teoría general del Derecho correspondiente. Desde el modelo de la autonomía social, por el contrario, el problema de la obligación política consiste en averiguar en qué medida puede conciliarse la autonomía de los individuos con la sumisión a las directivas de la autoridad política. Con este planteamiento, la justificación de la obediencia sólo puede derivarse de la legitimidad del poder político, la cual constituye un criterio extrínseco al concepto mismo de Derecho. Las teorías iuspositivistas, que niegan cualquier conexión conceptual entre el Derecho y la moral, suelen presuponer este modelo como la teoría correcta de la obligación política ${ }^{63}$. Según estas teorías, la identificación del Derecho válido de una comunidad política puede resolverse siempre a partir de criterios formales, suscepti-

${ }^{59}$ Law's Empire, op. cit., p. 190.

60 En este mismo sentido, $c f r$. J. DE LuCAs, 1985, «Una consecuencia de la tesis de los derechos: La desobediencia civil según Dworkin», Doxa, 2.

${ }^{61}$ Law's Empire, op. cit., p. 211.

62 Esta es igualmente la postura de RAWLS. Una consecuencia sorprendente de este planteamiento es que el individuo tiene un fundamento moral para mantener su propio juicio incluso cuando las instituciones autorizadas (normalmente, los tribunales) deciden que es errónea su interpretación de los principios comunes de justicia (cfr. R. DwORKIn, Taking Rights Seriously, op. cit., pp. 214-216; la cita remite a la versión original).

${ }^{63}$ Como ya expliqué en la nota 7 , prescindo aquí del positivismo denominado «incorporacionista o incluyente». Con todo, los defensores de esta clase de positivismo afirman que la inclusión de los principios de justicia como criterios de validez jurídica no impiden seguir manteniendo una concepción convencionalista del Derecho ( $c f r$. H. L. A. HART, 1994, «Postscript», en The Concept of Law, 2. a ed., Oxford: Clarendon Press; J. Coleman, 2001, The Practice of Principle, Oxford: Oxford University Press). Según estos autores, los principios de justicia pueden servir para la identificación del Derecho válido, no en virtud de su contenido moral, sino porque el propio sistema jurídico así lo ha establecido. De este modo, el positivismo incluyente otorga la primacía a los criterios formales de validez. 
bles de ser descritos sin recurrir a ninguna valoración moral. Desde esta perspectiva, la justificación de la obligatoriedad de las normas no forma parte integrante del fenómeno jurídico; ha de proceder, en todo caso, de una cualidad extrínseca a los hechos sociales que determinan la existencia y el contenido del Derecho ${ }^{64}$.

Sin embargo, desde una concepción positivista, cabe también negar la existencia de una obligación moral general de obediencia, incluso en un Estado democrático y razonablemente justo. Esta es la tesis de J. RAz, cuya teoría de la autoridad del Derecho no puede enmarcarse, por este motivo, dentro de lo que aquí hemos denominado el modelo de la autonomía social. Dada la enorme influencia de este autor en el ámbito del positivismo jurídico contemporáneo, y teniendo en cuenta que constituye uno de los máximos exponentes de la posición escéptica respecto a la existencia de la obligación política, quisiera terminar este trabajo tratando de dar réplica a su teoría.

\section{LA AUTORIDAD MORAL DEL DERECHO}

RAZ comparte con el modelo de la autonomía social dos elementos básicos. En primer lugar, plantea el problema de la obligación política como un conflicto entre la autoridad del Estado y la autonomía de los individuos. Tal planteamiento presupone que la libertad tiene un valor intrínseco, de modo que sólo cabe justificar la sumisión al Derecho como un acto de autonomía. El autor, no obstante, se aparta de dicho modelo en el modo de resolver dicho conflicto, puesto que se centra, como veremos, en una concepción de la autoridad política al servicio de la libertad individual. De acuerdo con su concepción, el ejercicio legítimo del poder político se limita a la protección y promoción de la «autonomía o racionalidad» de los individuos en la persecución de sus propios fines. En este sentido, RAZ se acerca al modelo del deber natural de justicia en su concepción de la libertad política, puesto que lejos de identificarla con la participación en la voluntad general, la define como «la libre elección de fines y relaciones», un ideal de vida autónoma que requiere, como condición necesaria, una voluntad independiente - es decir, la posibilidad de un obrar libre de coerción y manipulación ${ }^{65}$ -

En segundo lugar, RAZ considera la aceptación voluntaria como la única condición que podría justificar una obligación general de obediencia al Derecho. Se sitúa así en la tradición contractualista más ortodoxa, aunque su tesis principal afirme, en contra de dicha tradición, que la obligación política no tiene un alcance universal, sino que varía de un miembro a otro de la sociedad. Si esto último es así, asegura el autor, no es por-

${ }^{64}$ Desde un punto de vista positivista, la obediencia al Derecho significa sumisión al poder político, por lo que su justificación depende de la consonancia entre la voluntad política y la voluntad popular. Esta es la postura, por ejemplo, de R. SORIANO, cuya teoría general del Derecho abarca únicamente al aspecto normativo de la realidad jurídica, es decir, «el Derecho como norma y ordenamiento jurídico establecido por los poderes públicos en representación de la comunidad política» (Compendio de teoría general del Derecho, op. cit., p. 18). La clave, por tanto, para la fundamentación del deber jurídico, es la representatividad del poder. En un sistema político democrático, argumenta el autor, el ejercicio de la desobediencia a las normas es una «contradicción lógica». No obstante, la desobediencia al Derecho está justificada cuando hay «fisuras entre la voluntad política y la voluntad real de los ciudadanos». Se trata, pues, de arbitrar unas «mínimas condiciones» que aseguren la participación popular en los poderes públicos, así como el respeto de las minorías por las mayorías y la protección de los derechos fundamentales (ibídem, p. 230-233).

65 1986, The Morality of Freedom, Oxford: Clarendon Press, pp. 369-378. 
que su concepción se aparte de la teoría política moderna, sino porque «las sociedades en que vivimos son menos homogéneas, más controvertidas en cuanto a su propia identidad así como sobre el papel que juega el gobierno y el Derecho en la fábrica social» ${ }^{66}$.

Para discutir las ideas de RAZ, desarrollaré mi argumentación en torno a tres puntos: i) su teoría sobre la naturaleza del Derecho, donde el autor afirma que, como condición para poder reclamar autoridad general sobre los ciudadanos, todo sistema jurídico debe poder identificarse sin recurrir al juicio moral; ii) el enfoque instrumental del consentimiento y del Derecho, en el que RAZ señala las «condiciones morales» por las que un sistema jurídico puede reclamar autoridad legítima, y por tanto generar obligaciones morales; y iii) el enfoque no instrumental del consentimiento y del Derecho, donde considera el valor intrínseco de la sociedad política, y desde el que deriva la posibilidad de una actitud de «respeto hacia el Derecho».

i) Según RAZ, forma parte de la naturaleza del Derecho reclamar autoridad legítima sobre todos los ciudadanos de una comunidad política. En otras palabras, todo sistema jurídico afirma poseer un poder moral para obligar sistemáticamente a sus ciudadanos mediante directivas moralmente obligatorias ${ }^{67}$. Para ello, es necesario que el sistema jurídico en cuestión sea capaz de autoridad, lo cual exige, afirma RAZ, que los ciudadanos puedan identificar sus directivas sin recurrir al juicio moral. Esta condición refleja, según él, el papel mediador que ha de cumplir la autoridad política. Quien ejerce dicha autoridad se interpone entre los individuos y las razones (morales y no morales) que éstos tienen para actuar, de manera que pesa y valora por su cuenta las consideraciones aplicables en cada caso, emitiendo a la postre una directiva que pretende reemplazar esas razones con una instrucción única y excluyente. En esto consiste esencialmente la concepción de RAZ sobre la autoridad — que el autor denomina de «servicio» (the service conception of authority) —. Si los ciudadanos a los que se les aplica las directivas políticas necesitaran deliberar sobre las posibles razones que son aplicables al caso concreto para saber qué deben hacer, entonces la autoridad política no estaría actuando como tal. Aceptar la autoridad significa excluir de la deliberación las razones que la autoridad ya ha calibrado por su cuenta, asumiendo la nueva directiva obligatoria como la única razón para la acción.

Existen diversas críticas contra esta concepción de la autoridad, las cuales subrayan la importancia del juicio moral en la identificación de las normas jurídicas en un régimen constitucional ${ }^{68}$. Por mi parte, sin embargo, quisiera hacer en este punto una crítica inmanente a la teoría de RAZ, puesto que no parece que pueda armonizarse dicha

${ }^{66}$ Ethics in the Public Domain, op. cit., p. 354. Raz distingue dos clases de consideraciones sobre el consentimiento, y concluye que en la sociedad actual ninguna de ellas permite afirmar una obligación de obediencia que alcance a la totalidad de los miembros de una comunidad política, ni siquiera en un Estado razonablemente justo. La primera clase de consideraciones se engloban dentro del enfoque instrumental del consentimiento, propio del contractualismo de HOBBES y LOCKE, bajo el cual los ciudadanos aceptan la autoridad del Derecho por los beneficios que se derivan de su existencia —es decir, por su papel en la «fábrica social»—. El segundo es el planteamiento no instrumental, característico del contrato social de RoUSSEAU, en el cual el consentimiento se concibe como un elemento constitutivo de la relación entre los individuos y la comunidad — constitutivo al mismo tiempo de la sociedad civil y de la personalidad de quienes pertenecen a ella- (The Morality of Freedom, op. cit., p. 80).

${ }^{67}$ Ethics in the Public Domain, op. cit., pp. 215-220.

68 R. DworkIn, «Thirty Years On», op. cit., pp. 198-211; J. ColEman, The Practice of Principle, op. cit., pp. 124-133. 
concepción con el ideal de autonomía personal que trata supuestamente de proteger y promocionar. Una de las «funciones primarias» del Derecho que reconoce el autor es «proveer facilidades para los acuerdos privados entre individuos», es decir, ayudar a los individuos en la persecución de los fines de su elección ${ }^{69}$. Con este objetivo, el Derecho establece «las restricciones necesarias para proteger a una de las partes del acuerdo de ser explotada por la otra, y para proteger a terceras partes de las consecuencias injustas que les afectan ${ }^{70}$. Esta función es propia, en principio, del Derecho civil en general, y del Derecho contractual en particular. Pero creo que no nos apartaríamos demasiado de la teoría de RAZ si recondujéramos a este objetivo las otras tres funciones primarias que señala el autor (a saber, «la prevención de comportamientos indeseables y la protección de comportamientos deseables», «la provisión de servicios y la redistribución de bienes» $\mathrm{y}$ «la resolución de conflictos no regulados»), lo cual significaría que, en la medida en que esto es efectivamente así, el Derecho estaría orientado hacia la protección y promoción de la libertad como independencia. En cualquier caso, si ésta es al menos una de las funciones primarias del Derecho, su autoridad no puede consistir en pretender sustituir la deliberación de los ciudadanos con nuevas razones, sino que tendrá como fin el de ofrecer un marco legal dentro del cual sean los propios ciudadanos los que hagan sus acuerdos y persigan sus fines de acuerdo con su voluntad libre ${ }^{71}$. Pero si la autoridad no juega el papel mediador que le asigna RAZ, entonces la concepción de «servicio» no puede servir de base para postular la exclusión del juicio moral en la identificación del Derecho.

ii) Desde un punto de vista instrumental, dice RAz, existe obligación de obedecer sólo si el Derecho es capaz de justificar su autoridad de manera independiente a la voluntad de sus ciudadanos — por lo que, en este sentido, cabría hablar únicamente de un «consentimiento cualificado»—- ${ }^{72}$. Dicha justificación procede de la denominada «tesis de la justificación normal», según la cual sólo es posible afirmar la autoridad legítima de un sistema jurídico en la medida en que los individuos alcanzan mejor sus fines obedeciendo las normas que actuando por su cuenta.

Aunque este modo de fundamentar la autoridad política no remite directamente al consentimiento, sí permite reconciliar la sumisión al Derecho con el respeto a la autonomía de las personas. El Derecho ejerce una autoridad legítima, según RAZ, sólo cuando los individuos tienen más seguridad de actuar conforme a las razones correctas si obedecen las normas jurídicas que si intentan actuar conforme a dichas razones directamente ${ }^{73}$. De donde se sigue que el deber de obediencia al Derecho no tiene la misma

69 The Authority of Law, op. cit., p. 168. Raz denomina «funciones directas» del Derecho a aquellas que se satisfacen mediante la obediencia y la aplicación de sus normas. Entre ellas, el autor distingue entre las funciones primarias, que son aquellas «en las que se encuentra la razón y justificación de la existencia del Derecho», y las secundarias, que tienen que ver con el mantenimiento del sistema jurídico mismo.

70 Ibidem, p. 171.

${ }^{71}$ Como señala HAYEK, las normas jurídicas de un Estado de Derecho se diferencian de las simples órdenes respaldadas por la fuerza en el modo en que distribuyen unas y otras la voluntad y la deliberación entre quien manda y quien obedece (The Constitution of Liberty, op. cit., p. 150). En palabras de RAWLS, «aunque el ciudadano se somete en su conducta al juicio de la autoridad democrática, no somete a ella su propio juicio» (Collected Papers, op. cit., p. 181).

${ }_{72}$ Cfr. The Morality of Freedom, op. cit., p. 90; Ethics in the Public Domain, op. cit., pp. 364-366.

73 Ethics in the Public Domain, op. cit., pp. 365-366. Toda vez que se cumple la condición de legitimidad, los ciudadanos pueden aceptar la autoridad política sin menoscabo de su autonomía como seres racionales. RAZ 
extensión en todos los ámbitos ni para todos los ciudadanos. La tesis de la justificación normal «conduce a la conclusión de que la extensión de la autoridad política varía de individuo a individuo, y en la mayoría de los casos es más limitada de lo que ella misma reclama para sí» ${ }^{74}$. Por otra parte, los Estados cumplen algunas de sus principales funciones sin necesidad de ejercer ningún tipo de autoridad, es decir, sin que el Derecho sea fuente de obligación alguna. Así, por ejemplo, cuando se limita a hacer cumplir lo que la moral exige previa e independientemente, o cuando establece y mantiene esquemas de cooperación social, el Derecho no hace más que imponer obligaciones que ya existen por razones morales independientes ${ }^{75}$.

Varios autores han puesto de relieve la falta de sintonía entre, por un lado, la forma parcial y cualificada que tiene la obligación política en la teoría de RAZ, y, por otro, el tipo de autoridad moral que el Derecho reclama para sí $^{76}$. La concepción de la autoridad de RAZ es más teórica que práctica, tiene que ver más con las instrucciones de un experto (o las recomendaciones de un amigo) que con los imperativos de una voluntad legisladora. Por eso no da cuenta ni de la capacidad del Derecho para establecer genuinas obligaciones prácticas, ni del alcance de su autoridad.

En mi opinión, estas críticas están bien fundadas, y pueden servir de base para defender el modelo del deber natural de justicia, así como para cuestionar la tajante distinción que hace el autor entre las consideraciones instrumentales y no instrumentales sobre el Derecho. En efecto, en el argumento que ofrece el modelo del deber natural se dan de la mano ambos tipos de consideraciones. Dicho argumento es, en principio, instrumental. No se trata de defender la obediencia al Derecho justo como un fin en sí mismo, sino como un medio para crear las circunstancias en las que los individuos pueden formar y perseguir libremente sus propios fines. No obstante, al ser un medio institucional esencial para la realización de la libertad como independencia, el Derecho justo posee también un valor básico u originario ${ }^{77}$. En este sentido, su fuerza normativa no puede depender del grado de «servicio» que reporte a los individuos en el logro de sus fines. Parece más razonable pensar que si el Derecho justo tiene un valor originario, sus normas han de ser moralmente válidas, es decir, que las obligaciones que pretenden crear deben ser genuinas obligaciones ${ }^{78}$ Conviene recordar que lo que aquí de-

añade, no obstante, a esta condición la «cláusula de la autonomía»: el Estado sólo puede tener autoridad legítima sobre aquellas materias en las que es más importante actuar de acuerdo con las razones correctas que decidir por uno mismo. De esta forma, el autor pretende proteger y fomentar la autonomía como ideal de vida buena. Sin embargo, no creo que éste sea el mejor modo de garantizar y promover la autonomía como capacidad para elegir qué es bueno en la vida. En todo caso, la distinción entre una y otra forma de entender el valor de la autonomía es precisamente lo que separa al modelo de la autonomía social del modelo del deber natural de justicia.

${ }_{74}$ The Morality of Freedom, op. cit., p. 80.

75 The Authority of Law, op. cit., pp. 245-249.

${ }^{76}$ S. PERRY, «Law and Obligation», op. cit., pp. 280-281; en un sentido similar, P. SOPER, 1989, «Legal Theory and the Claim of Authority», Philosophy E Public Affairs, 18, 3 .

77 Aquí me valgo de un argumento que utiliza RawLs para defender el carácter básico de las libertades políticas. Según RAWLS, a pesar de que el principal papel de estas libertades es la preservación de los demás derechos, las incluye entre las libertades básicas en el Primer Principio de Justicia, puesto que para ello sólo se necesita «que sean suficientemente importantes en tanto que medios institucionales esenciales para garantizar las otras libertades» (Political Liberalism, op. cit., p. 299, la cursiva es mía).

${ }_{78}$ Precisamente por poseer un valor básico o fundamental, el Derecho debe ser obedecido independientemente de las consecuencias efectivas que pueda tener nuestra desobediencia en el sostenimiento de las instituciones justas. 
nominamos «Derecho justo» es aquél que satisface el principio de la integridad de la justicia, lo cual supone, como ya vimos, tratar con igual consideración y respeto a todos los miembros de la sociedad. Ésta es la única propiedad moral que permite al Derecho cumplir con la función esencial que le es propia. No hay ninguna otra consideración moral relevante para afirmar la obligación de obedecerlo ${ }^{79}$.

iii) Bajo una perspectiva no instrumental, RAZ considera que la obligación política puede surgir a partir del valor intrínseco que tiene la comunidad política como foco de identificación de las personas ${ }^{80}$. Situado en esta perspectiva, el autor reconoce la dificultad de basar en un acto de consentimiento la obligación de obedecer el Derecho. Sin embargo, afirma que aún es posible encontrar otro modo de adquirir obligaciones políticas voluntarias o cuasi-voluntarias. Por analogía con los vínculos familiares o de amistad, donde los individuos se ven obligados a hacer ciertas acciones como expresión de la relación que les une con sus familiares o amigos, los ciudadanos pueden verse obligados a obedecer el Derecho como expresión de una actitud de identificación o lealtad hacia su comunidad política.

Los deberes de lealtad, piensa RAZ, tienen un valor intrínseco — puesto que son parte constitutiva de unas relaciones que los individuos valoran por sí mismas-, pero no por ello dejan de ser cuasi-voluntarios - dado que surgen a partir de relaciones no obligatorias-. En el caso de la identificación con la propia comunidad política, RAz añade la condición de que la sociedad sea razonablemente justa, pues de otro modo, dice el autor, la identificación no es moralmente valiosa. El «respeto hacia el Derecho» viene a ser, por tanto, un aspecto de ese sentido de pertenencia. Significa que uno asume la obligación de obedecer el Derecho como una medio apropiado para expresar su confianza en la justicia y la razonabilidad de los órganos formales de su comunidad. Esta actitud de respeto no deriva de ningún acto concreto de consentimiento. Al igual que la amistad, necesita tiempo para crecer y desarrollarse. Pero funda una obligación de obediencia cuasi-voluntaria, puesto que nadie está obligado a sentir un vínculo de pertenencia con su comunidad.

Sin embargo, creo que puede asumirse la analogía con la fraternidad o la amistad sin aceptar, por añadidura, que la obligación política es cuasi-voluntaria. De hecho, la concepción de DwORKIN se basa en la misma idea de incluir la obediencia al Derecho entre las obligaciones asociativas, y sin embargo se trata de una concepción perfectamente asumible desde el modelo del deber natural de justicia (o así al menos lo hemos argumentado). Lo decisivo es que ambos autores atribuyen la obligación moral de obediencia a un sentido de lealtad o respeto hacia la propia comunidad política, pero mien-

${ }^{79}$ En este punto disiento de PERRY. Según este autor, el Derecho debe considerarse moralmente obligatorio por ser parte constitutiva de la comunidad política, la cual tiene un «valor intrínseco» para los ciudadanos («Associative Obligations and the Obligation to Obey the Law», op. cit., pp. 200-201). En mi opinión, la comunidad política sólo tiene valor intrínseco en el modelo de la autonomía social, es decir, cuando los ciudadanos valoran el «gobernarse a sí mismos como comunidad mediante normas que ellos mismos crean». Otra cosa distinta es valorar la comunidad política como un «bien único y necesario para que los individuos vivan vidas completas o se desarrollen completamente como seres humanos o racionales». Aunque el autor los equipare, creo que este segundo caso hace referencia a la vida no pública de las personas, donde el Derecho tiene un valor instrumental, aunque decisivo, para los ciudadanos.

${ }^{80}$ Cfr. «Respect for Law», en The Authority of Law, op. cit., pp. 250-262; The Morality of Freedom, op. cit., pp. 94-99; Ethics in the Public Domain, op. cit., pp. 353-354. 
tras RAZ afirma que dicha lealtad consiste en una actitud meramente permisible, que expresa la identificación cuasi-voluntaria de los individuos con su sociedad, DwORKIN afirma que se trata de es un deber moral, cuyo origen es la integridad política de las instituciones.

Lo cual no quiere decir que el modelo del deber natural no otorgue ningún papel a la identificación cuasi-voluntaria con la propia comunidad política - siempre que ésta sea razonablemente justa-. Los ciudadanos pueden sentirse identificados con los actos políticos formales de sus instituciones mediante lo que DwORKIN denomina un «sentido de integración ${ }^{81}$. Cuando esto ocurre, los ciudadanos reconocen la importancia que tiene la comunidad política - y, más concretamente, el grado de justicia de las instituciones- en la elección y persecución de sus propios fines. Como bien señala RAZ, la aceptación de ese vínculo transforma la actitud de los individuos hacia el Derecho - cabría decir incluso que su difusión entre los miembros de la comunidad promueve decisivamente el ideal de la autonomía social—. Sin embargo, sentido de identificación no altera en ningún caso la fuerza normativa de las demandas justas de la vida social.

${ }^{81}$ 2000, cfr. «Liberal Community», en Sovereign Virtue, Cambridge: Mass., Harvard University Press ( $\mathrm{La}$ comunidad liberal, trad. esp. C. Montilla, Santa Fe de Bogotá, Universidad de los Andes, 1996). 
